\title{
Characterization of Polyphosphoesters by Fourier Transform Ion Cyclotron Resonance Mass Spectrometry
}

\author{
Malgorzata A. Kaczorowska and Helen J. Cooper \\ School of Biosciences, College of Life and Environmental Sciences, University of Birmingham, Birmingham, \\ United Kingdom
}

FT-ICR mass spectrometry, together with collision-induced dissociation and electron capture dissociation, has been used to characterize the polyphosphoester poly[1,4-bis(hydroxyethyl) terephthalate-alt-ethyloxyphosphate] and its degradation products. Three degradation pathways were elucidated: hydrolysis of the phosphate-[1,4-bis(hydroxyethyl)terephthalate] bonds; hydrolysis of the phosphate-ethoxy bonds; and hydrolysis of the ethyl-terephthalate bonds. The dominant degradation reactions were those that involved the phosphate groups. This work constitutes the first application of mass spectrometry to the characterization of polyphosphoesters and demonstrates the suitability of high mass accuracy FT-ICR mass spectrometry, with CID and ECD, for the structural analysis of polyphosphoesters and their degradation products. (J Am Soc Mass Spectrom 2009, 20, 2238-2247) (C) 2009 American Society for Mass Spectrometry

$\mathrm{P}$ olyphosphoesters (PPEs) are polymers that contain repeated phosphoester bonds in the backbone and which are well-suited for numerous biological and pharmaceutical applications [1,2]. They are particularly attractive for drug and gene delivery, and tissue engineering [3-10] due to their chemical properties and biocompatibility. PPEs are characterized by structural versatility-the result of pentavalent phosphorus atoms in the backbone-enabling modification of their physicochemical properties and introduction of bioactive molecules [1, 6, 11]. Even small variations in the structure of polyphosphoesters can dramatically influence their interactions with biological systems [5].

One of the important features of PPEs, which enables their use for biomedical applications, is biodegradability. PPEs biodegrade through hydrolysis, and possibly enzymatic digestion, of phosphate bonds under physiologic conditions [2, 12]. The in vitro degradation behavior of PPEs has been characterized by monitoring changes in mass by gel permeation chromatography [1]. However, information regarding overall molecular weight change is insufficient if the PPE is to be considered for drug or gene delivery. A PPE can only be applied as such if all its degradation products and their properties, such as cytotoxicity, are known. Clearly, polymers with satisfactory biocompatibility but toxic degradation products will not find biomedical applica-

Address reprint requests to Dr. H. J. Cooper, School of Biosciences, University of Birmingham, Edgbaston, Birmingham B15 2TT, UK. E-mail: H.J.Cooper@bham.ac.uk tions [13]. Similarly, the rate of degradation of the polymer must be physiologically suitable for the application.

As the performance of PPEs in biomedical applications depends on their properties, there is a need for fast and simple techniques for characterization of the polymer structure, its purity, and the products of degradation. Mass spectrometry is a valuable tool for the characterization of chemical polymers [14], providing information about the molecular weight distribution of polymers, and their structural and elemental composition [15]. Simonsick and Petkovska [16] reported detailed structural elucidation of polyesters and acrylates by use of Fourier transform ion cyclotron resonance (FT-ICR) mass spectrometry. FT-ICR mass spectrometry was also used by Cerda and coworkers [17] for sequencing specific copolymer oligomers by electron capture dissociation (ECD) and examining the fragmentation behavior of poly(ethylene glycol) (PEG) ions by both collision-induced dissociation (CID) and ECD [18]. Previous work in our laboratory, and others, demonstrated the suitability of FT-ICR with ECD and CID for the characterization of dendrimers [19-21].

Although mass spectrometry has been widely used for the characterization of many different types of polymers, so far, characterization of polyphosphoesters has been achieved solely by nuclear magnetic resonance (NMR) spectroscopy, gel permeation chromatography (GPC), and high-performance liquid chromatography (HPLC) methods [1]. Zhao and coworkers studied the in vitro and in vivo degradation of a poly(lactide-coethylphosphate) copolymer, the bulk of which was PDLA [poly(D,L-lactide)], using gel permeation chromatography, ${ }^{1} \mathrm{H}$ and ${ }^{31} \mathrm{P}$ NMR weight loss measure- 
ments, and differential scanning calorimetry [22]. Their results indicated a two stage degradation of the PPE: In the first (fast) stage, degradation predominantly occurs at the phosphate-lactide bonds with minor degradation at phosphate-ethoxy bonds. In the second (slower) stage, hydrolysis of the PDLA occurred.

Here, we present the FT-ICR mass spectrometry and tandem mass spectrometry (CID and ECD) of the polyphosphoester poly[1,4-bis(hydroxyethyl)terephthalate-altethyloxyphosphate], see Scheme 1 . The results show that this PPE degrades either during storage in air or in the solvent conditions used here. Clearly, the solvent conditions here (chloroform/methanol/water) do not reflect the environment experienced by a polyphosphoester delivering a drug in the human body. Nevertheless, we show that mass spectrometry analysis provides valuable information about the polyphosphoester structures and enables determination of the degradation pathways of the PPE. Three degradation pathways were observed: hydrolysis of the phosphate-[1,4-bis(hydroxyethyl)terephthalate] bonds; hydrolysis of the phosphate-ethoxy bonds; and hydrolysis of the ethyl-terephthalate bonds. The dominant degradation reactions were those that involved the phosphate groups. A comprehensive time-course study of the degradation profile of the PPE is beyond the scope of this paper; however we demonstrate the suitability of the combination of high mass accuracy FT-ICR mass spectrometry, CID, and ECD, for the structural analysis of polyphosphoesters and their degradation products.

\section{Experimental}

\section{Sample Preparation}

Poly[1,4-bis(hydroxyethyl)terephthalate-alt-ethyloxyphosph ate] was purchased from Sigma-Aldrich (Poole, Dorset, UK) and used without further purification. The polyphosphoester was dissolved in chloroform (Sigma-Aldrich Co., St. Louis, MO, USA) and diluted to a concentration of $\sim 10 \mathrm{pmol} / \mu \mathrm{L}$ in methanol (FisherScientific, Loughborough, UK) and acetic acid (FisherScientific) (30:70:2, vol/ vol).

To promote cationization of poly[1,4-bis(hydroxyethyl) terephthalate-alt-ethyloxyphosphate], sodium iodide (Fluka Chemie AG., Buchs, Switzerland), used without further purification, and dissolved in water (J. T. Baker, Deventer, Holland), was added to the electrospray solution for ECD and CID of doubly-charged ions. The final electrospray solution for these experiments contained: polyphosphoester dissolved in chloroform, NaI

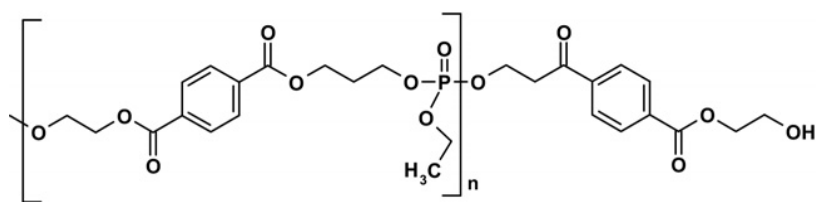

Scheme 1. Structure of poly[1,4-bis(hydroxyethyl)terephthalate-altethyloxyphosphate]. dissolved in water, methanol, and acetic acid (30:10: 70:2, vol/vol). The concentration of the polyphosphoester in the final electrospray mix was $\sim 10 \mathrm{pmol} / \mu \mathrm{L}$. The molar ratio of polyphosphoester to $\mathrm{NaI}$ was $\sim 1: 1$.

\section{Mass Spectrometry}

All mass spectrometry experiments were performed on a Thermo Finnigan LTQ FT mass spectrometer (Thermo Fisher Scientific, Bremen, Germany). The Advion Biosciences Triversa Nanomate electrospray source (Advion Biosciences, Ithaca, NY, USA) was used to introduce samples to the mass spectrometer. Data acquisition and analysis was performed using the Xcalibur 2.0 software (Thermo Fisher Scientific). Mass spectra in all experiments (MS and MS/MS) were acquired at a resolution of 100000 at $m / z 400$.

$E C D$. The ions of desired $m / z$ value were selected and isolated in the linear ion trap and transmitted to the ICR cell for ECD. Isolation width for ions of interest was 10 $m / z$. Automatic gain control (AGC) was used to accumulate sufficient precursor ions (target value $1 \times 10^{6}$ ). Electrons were generated on the surface of an indirectly heated barium tungsten cylindrical dispenser cathode (Heat Wave Labs, Inc, Watsonville, CA). The current across the electrode was $\sim 1.1 \mathrm{~A}$. Precursor ions were irradiated with electrons for $70 \mathrm{~ms}$.

CID. All CID experiments were performed in the front-end linear ion trap and the fragments transferred to the ICR cell for detection. Isolation width was $10 \mathrm{~m} / \mathrm{z}$. AGC target value was $1 \times 10^{6}$. Helium gas at a normalized collision energy of $35 \%$ was used for all CID experiments.

All the MS and MS/MS spectra were averaged over 30 scans and analyzed manually. Each ECD and CID scan consisted of five co-added microscans.

\section{Results and Discussion}

Poly[1,4-bis(hydroxyethyl)terephthalate-alt-ethyloxyphosph ate] is a water-insoluble, biodegradable polymer. Electrospray ionization of poly[1,4-bis(hydroxyethyl)terephthalatealt-ethyloxyphosphate], (Scheme 1), in chloroform/ methanol/acetic acid solution, leads to the formation of predominantly singly-charged ions. The mass spectrum is shown in Figure 1a.

The proposed structures of the ions, in order of increasing $\mathrm{m} / \mathrm{z}$ ratio, are shown in Scheme 2 . Degradation product assignments were made on the basis of accurate mass measurement and CID of singly-charged ions (see below), and verified by comparison of observed and expected isotope patterns. The degradation pathways observed for poly[1,4-bis(hydroxyethyl)terephthalate-altethyloxyphosphate] are shown in Scheme 3.

The mass spectrum of poly[1,4-bis(hydroxyethyl) terephthalate-alt-ethyloxyphosphate] can be divided into four main regions, which relate to the number of 

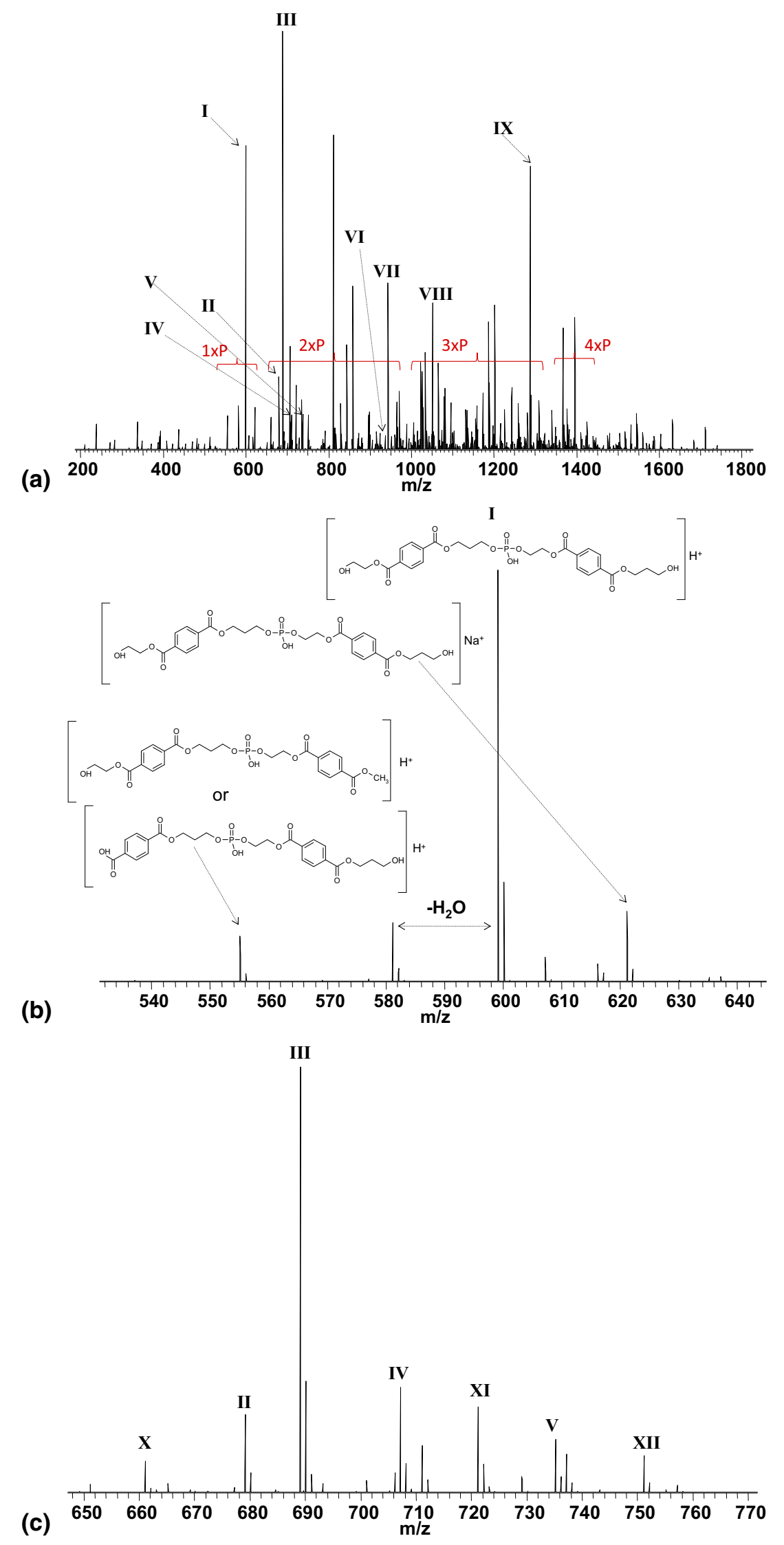

Figure 1. (a) Electrospray FT-ICR mass spectrum of poly[1,4-bis(hydroxyethyl)terephthalate-altethyloxyphosphate] in chloroform/methanol/acetic acid solution; (b) expanded $\mathrm{m} / \mathrm{z}$ region 550 to 650 ; and (c) expanded $\mathrm{m} / \mathrm{z}$ region 650 to 770 . 


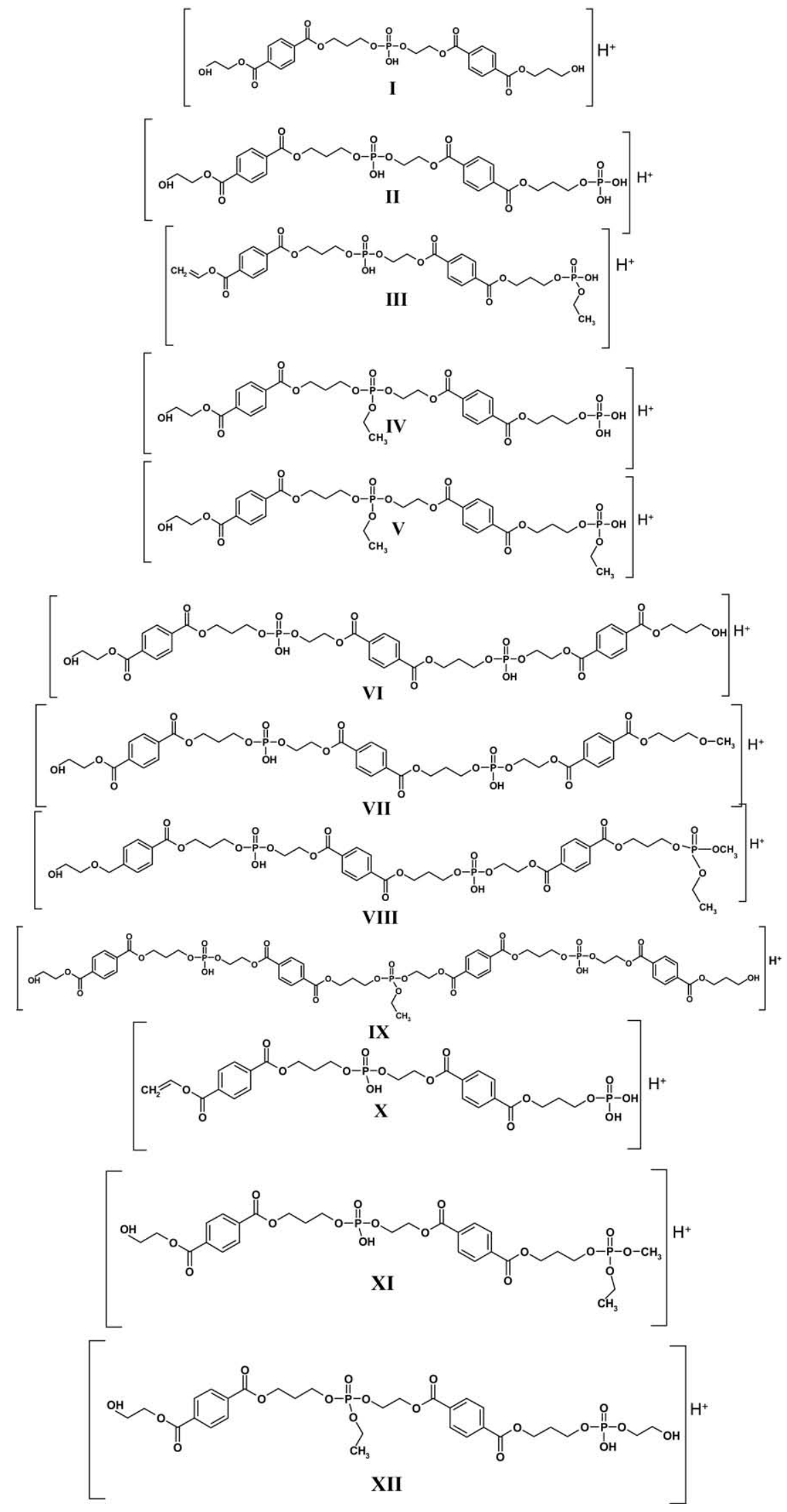

Scheme 2. Structures of singly-protonated degradation products of poly[1,4-bis(hydroxyethyl) terephthalate-alt-ethyloxyphosphate]. 


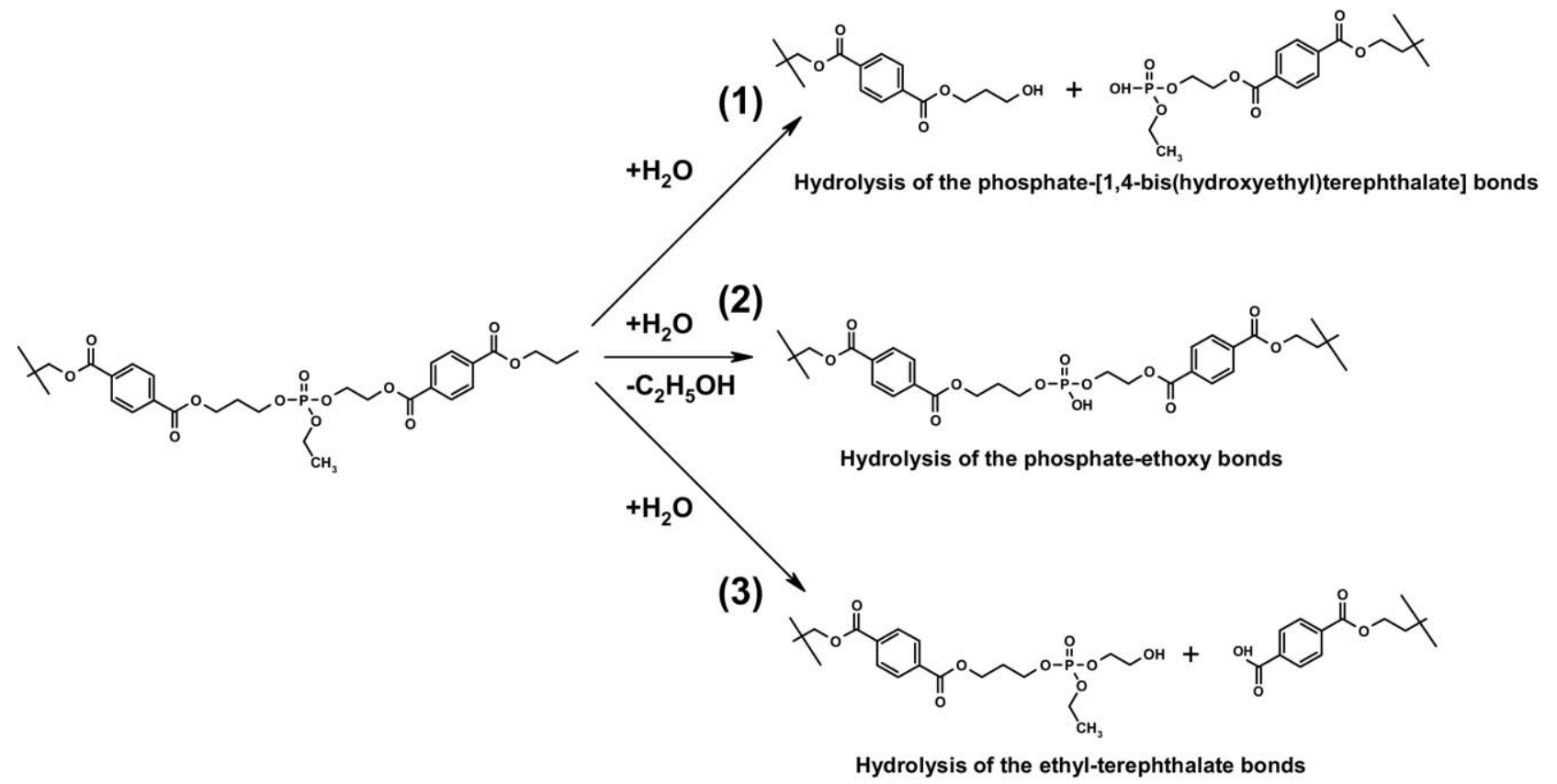

Scheme 3. Degradation pathways of poly[1,4-bis(hydroxyethyl)terephthalate-alt-ethyloxyphosphate].

phosphate groups present in the degradation products (see Figure 1a). In the first region, from about $m / z 550$ to 650 (denoted $1 \times \mathrm{P}$ ), only those species containing a single phosphate group were detected. Detailed assignments for this part of the mass spectrum are shown in Figure $1 b$. The most abundant peak $\left(\mathrm{m} / \mathrm{z}_{\text {meas }} 599.1544\right.$, $\left.\mathrm{m} / \mathrm{z}_{\text {calc }} 599.1530\right)$ corresponds to a singly-charged ion containing a phosphate group (loss of $\mathrm{C}_{2} \mathrm{H}_{4}$ from ethyloxyphosphate group). The structure of this ion is shown in Scheme 2 (denoted I). Species I appears to be formed as a result of hydrolysis of the phosphate-[1,4bis(hydroxyethyl)terephthalate] bond (route 1 in Scheme 3) and the phosphate-ethoxy bond (route 2 in Scheme 3) in the PPE. Similar degradation pathways have been reported for poly(lactide-co-ethylphosphate) [22]. The peak observed at $\mathrm{m} / \mathrm{z} 581.1436\left(\mathrm{~m} / \mathrm{z}_{\text {calc }} 581.1424\right)$ corresponds to the loss of a water molecule from $I$. The water molecule could be subtracted from either end of I, and the peak may correspond to populations of both structures, however there is no peak corresponding to the loss of two water molecules from I. The peak observed at $m / z 555.1281\left(m / z_{\text {calc }} 555.1268\right)$ can be assigned to one of two degradation product ions formed either by degradation pathway 3 combined with degradation pathway 1 or degradation pathway 1 combined with degradation pathway 3 (see Scheme 3 ). Both structures are possible, and we are not able on the basis of this experiment to clarify which structure is observed. It may be possible to differentiate between the two by $\mathrm{MS}^{3}$ or nuclear magnetic resonance (NMR) spectroscopy. The peak at $\mathrm{m} / \mathrm{z} 621.1365\left(\mathrm{~m} / \mathrm{z}_{\text {calc }} 621.1349\right)$ corresponds to sodiated $\mathbf{I}$.

The CID mass spectrum of protonated $\mathbf{I}\left(\left(\mathrm{m} / \mathrm{z}_{\text {meas }}\right.\right.$ $\left.599.1544, m / z_{\text {calc }} 599.1530\right)$ is shown in Figure 2a. Pro- posed structures are shown. The most abundant peak at $m / z 237.0756\left(m / z_{\text {calc }} 237.0763\right)$ can be assigned to a fragment ion formed as a result of a six-center pericyclic reaction. The complementary fragment, with additional water loss, is observed at $m / z 345.0732\left(\mathrm{~m} / \mathrm{z}_{\text {calc }} 345.0739\right)$. The minor signal at $\mathrm{m} / \mathrm{z} 581.1414\left(\mathrm{~m} / \mathrm{z}_{\text {calc }} 581.1424\right)$ can be assigned to loss of one molecule of water from the precursor ion. The peak at $\mathrm{m} / \mathrm{z} 211.0312\left(\mathrm{~m} / \mathrm{z}_{\text {calc }}\right.$ 211.0371 ) can be assigned to a fragment ion formed as a result of two processes; cleavage between the phenyl and carbonyl group in the hydroxyethylterephthalate and a six-center pericyclic reaction.

The second region of the mass spectrum of the PPE (denoted 2xP in Figure 1a), m/z 650 to $\sim 1000$, shows peaks corresponding to species containing two phosphate groups. As might be expected, the number of observed species is much higher than for the $1 \times P$ region. PPE degradation products containing two phosphate groups, one phosphate and one ethyloxyphosphate group, and two ethyloxyphosphate groups are observed, e.g., species II (see Scheme 2) at $\mathrm{m} / \mathrm{z} 679.1213$ $\left(\mathrm{m} / \mathrm{z}_{\text {calc }} 679.1193\right), \mathbf{I V}$ where the precise location of the ethyloxyphosphate group is unknown, at $m / z 707.1529$ $\left(\mathrm{m} / \mathrm{z}_{\text {calc }} 707.1506\right)$, and $\mathbf{V}$ at $\mathrm{m} / \mathrm{z} 735.1843\left(\mathrm{~m} / \mathrm{z}_{\text {calc }} 735.1819\right)$, respectively. Furthermore, degradation product ions containing two identical phosphate/ethyloxyphosphate groups can differ by the location along the backbone of these groups. For example, the peak at $m / z 929.2077$ corresponds to species VI $\left(\mathrm{m} / \mathrm{z}_{\text {calc }} 929.2034\right)$ in which both phosphate groups are internal, whereas the peak at $m / z 679.1213$ corresponds to species II in which one of the phosphate groups is situated at the terminus. The degradation products VI and II both arise via degradation pathway 1 (Scheme 3 ). Often, the precise connec- 

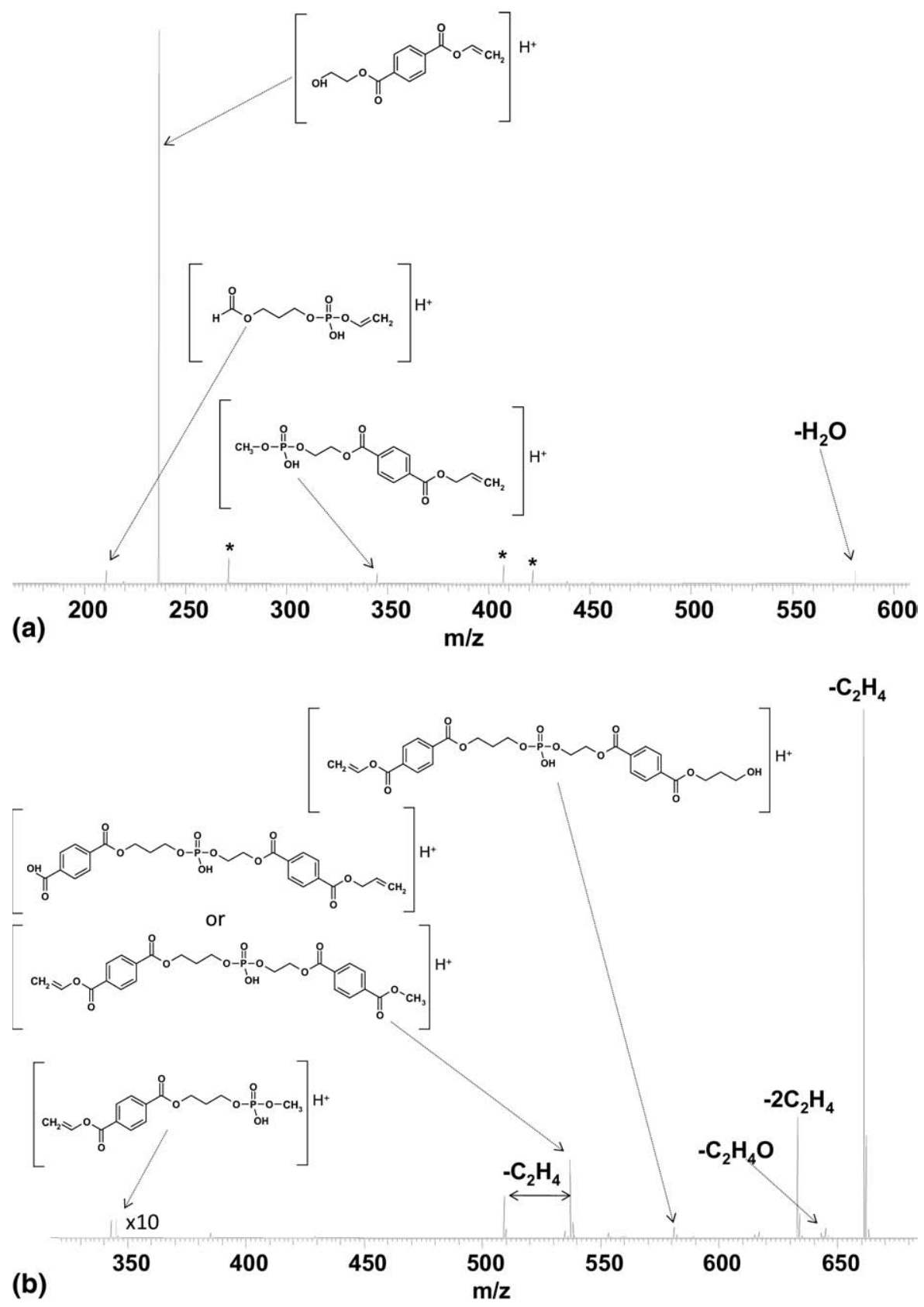

Figure 2. CID FT-ICR mass spectra of (a) singly-protonated I ions (artefacts are denoted with an asterisk) and (b) singly-protonated III ions.

tivity of the observed PPE degradation products is unknown; for example, the intense signal at $\mathrm{m} / \mathrm{z}$ $943.2231\left(\mathrm{~m} / \mathrm{z}_{\text {calc }} 943.2191\right)$ could be assigned to a species with two phosphate groups and a methoxy group $\left(-\mathrm{OCH}_{3}\right.$ from the solvent) at one end of the polymer fragment; species VII shown in Scheme 2 represents one potential structure.

The region of the mass spectrum from $\mathrm{m} / \mathrm{z} 650$ to 750 , shown in Figure 1c, nicely illustrates the diversity of the simplest degradation products containing two phosphate groups. The base peak at $m / z_{\text {meas }} 689.1419\left(\mathrm{~m} / \mathrm{z}_{\text {calc }}\right.$ 689.1400) can be assigned to the singly-charged species III (see Scheme 2), which contains one ethyloxyphos- phate and one phosphate group. CID of III (see below) suggests that the ethyloxyphosphate group is located at the terminus of the polymer. Species III is the result of degradation at the phosphate-[1,4-bis(hydroxyethyl) terephthalate] and phosphate-ethoxy bonds (routes 1 and 2 in Scheme 3), with additional loss of a water molecule. The hydrated analogue of III is observed at $m / z 707.1529$ (species IV, discussed above). Polyphosphoester species with two phosphate groups and two ethyloxyphosphate groups are also observed; II and V respectively. The minor peak at $\mathrm{m} / \mathrm{z} 751.1793\left(\mathrm{~m} / \mathrm{z}_{\text {calc }}\right.$ 751.1768), assigned as XII, deserves special attention because it is the combined result of three different 
degradation pathways. First, there is hydrolysis of the phosphate-[1,4-bis(hydroxyethyl)terephthalate] bond (route 1 in Scheme 3). Second, there is reduction of the ethyloxyphosphate (route 2 in Scheme 3). Finally, there is hydrolysis of the ethyl-terephthalate bond as shown in route 3 , Scheme 3 . The phosphate group is not involved in that degradation reaction.

The CID mass spectrum of protonated polyphosphoester III is shown in Figure 2b. The spectrum is dominated by a peak at $m / z 661.1051\left(\mathrm{~m} / \mathrm{z}_{\text {calc }} 661.1088\right)$, which is the result of loss of $\mathrm{C}_{2} \mathrm{H}_{4}$, presumably from the ethyloxyphosphate group of the precursor ion. The peak at $\mathrm{m} / \mathrm{z} 633.0757\left(\mathrm{~m} / \mathrm{z}_{\text {calc }} 633.0774\right)$ is the result of loss of two molecules of $\mathrm{C}_{2} \mathrm{H}_{4}$ from the precursor ion. Cleavage of the ethyloxyphosphate-[1,4-bis(hydroxyethyl)terephthalate] bond leads to loss of the neutral fragment: $\left[\left\{\mathrm{P}(\mathrm{O})_{2}\right\} \mathrm{OCH}_{2} \mathrm{CH}_{3}\right]$, forming the fragment ion observed at $\mathrm{m} / \mathrm{z} 581.1417\left(\mathrm{~m} / \mathrm{z}_{\text {calc }} 581.1424\right)$. This fragmentation process suggests that the ethyloxyphosphate group is located at the terminus of polyphosphoester fragment III. The equivalent fragment in which the ethyloxyphosphate group is centrally located is not observed. However, the peak at $m / z 581$ may arise through loss of $\mathrm{C}_{2} \mathrm{H}_{4}$ separate to terephthalate-phosphate cleavage. The peak at $\mathrm{m} / \mathrm{z} 537.1151\left(\mathrm{~m} / \mathrm{z}_{\text {calc }} 537.1162\right)$ can be assigned to a fragment ion containing a centrallylocated phosphate group. That fragment is likely the result of a six-center pericyclic reaction; loss of neutral fragment: $\left[\mathrm{CH}_{2}=\mathrm{CH}-\mathrm{O}-\left\{\mathrm{P}(\mathrm{O})\left(\mathrm{OCH}_{2} \mathrm{CH}_{3}\right)\right\}-\mathrm{OH}\right]$ from the precursor ion occurs. Alternatively, the fragment may be the result of two cleavages; one at the ethyloxyphosphate-[1,4-bis(hydroxyethyl)terephthalate] bond (with loss of the ethyloxyphosphate group), and a second between the oxygen atom and $\mathrm{CH}_{2}=\mathrm{CH}-$ group (with loss of $\mathrm{C}_{2} \mathrm{H}_{2}$ ). The fragment ion of $\mathrm{m} / \mathrm{z}$ 509.0850 is the result of loss of $\mathrm{C}_{2} \mathrm{H}_{4}$ from the ion of $\mathrm{m} / \mathrm{z}$ 537.

The third region of the mass spectrum of poly[1,4bis(hydroxyethyl)terephthalate-alt-ethyloxyphosphate] from $m / z 1000$ to $\sim 1350$ (denoted 3xP in Figure 1a) shows PPE species containing three phosphate/ethyloxyphosphate groups. The most intense signal at $\mathrm{m} / \mathrm{z} 1287.2908$ $\left(\mathrm{m} / \mathrm{z}_{\text {calc }} 1287.2852\right)$ can be assigned to the species IX (see Figure 1a, Scheme 2) containing two phosphate groups and one ethyloxyphosphate group. The precise location of the ethyloxyphosphate group is unknown. As for the $2 \times P$ region, the $3 \times \mathrm{P}$ region comprises a variety of different degradation products, which are mainly the result of hydrolysis at phosphate-[1,4-bis(hydroxyethyl)terephthalate] bonds, together with phosphate, ethyloxyphosphate, and mixed phosphate/ethyloxyphosphate groups (routes 1 and 2 in Scheme 3).

The most intense peaks in the fourth region of the mass spectrum (denoted $4 \times \mathrm{P}$ in Figure 1a) occur at $\mathrm{m} / \mathrm{z}$ 1395.2827 and 1367.2561, and can be assigned to species containing two phosphate groups and two ethyloxyphosphate groups $\left(\left(\mathrm{m} / \mathrm{z}_{\text {calc }} 1395.2827\right)\right.$, and three phosphate groups and one ethyloxyphosphate group $\left(\mathrm{m} / \mathrm{z}_{\text {calc }}\right.$ 1367.2514), respectively. The species containing four phosphate groups is also observed $\left(\mathrm{m} / \mathrm{z}_{\text {meas }} 1339.2272\right.$, $\left.\mathrm{m} / \mathrm{z}_{\text {calc }} 1339.2203\right)$, however species containing four ethyloxyphosphate groups are not.

The results of mass spectrometry experiments performed for [1,4-bis(hydroxyethyl)terephthalatealt-ethyloxyphosphate] suggests that degradation of this polymer occurs mainly at the phosphate-[1,4-bis (hydroxyethyl)terephthalate] and phosphate-ethoxy bonds (routes 1 and 2 in Scheme 3). Most of the

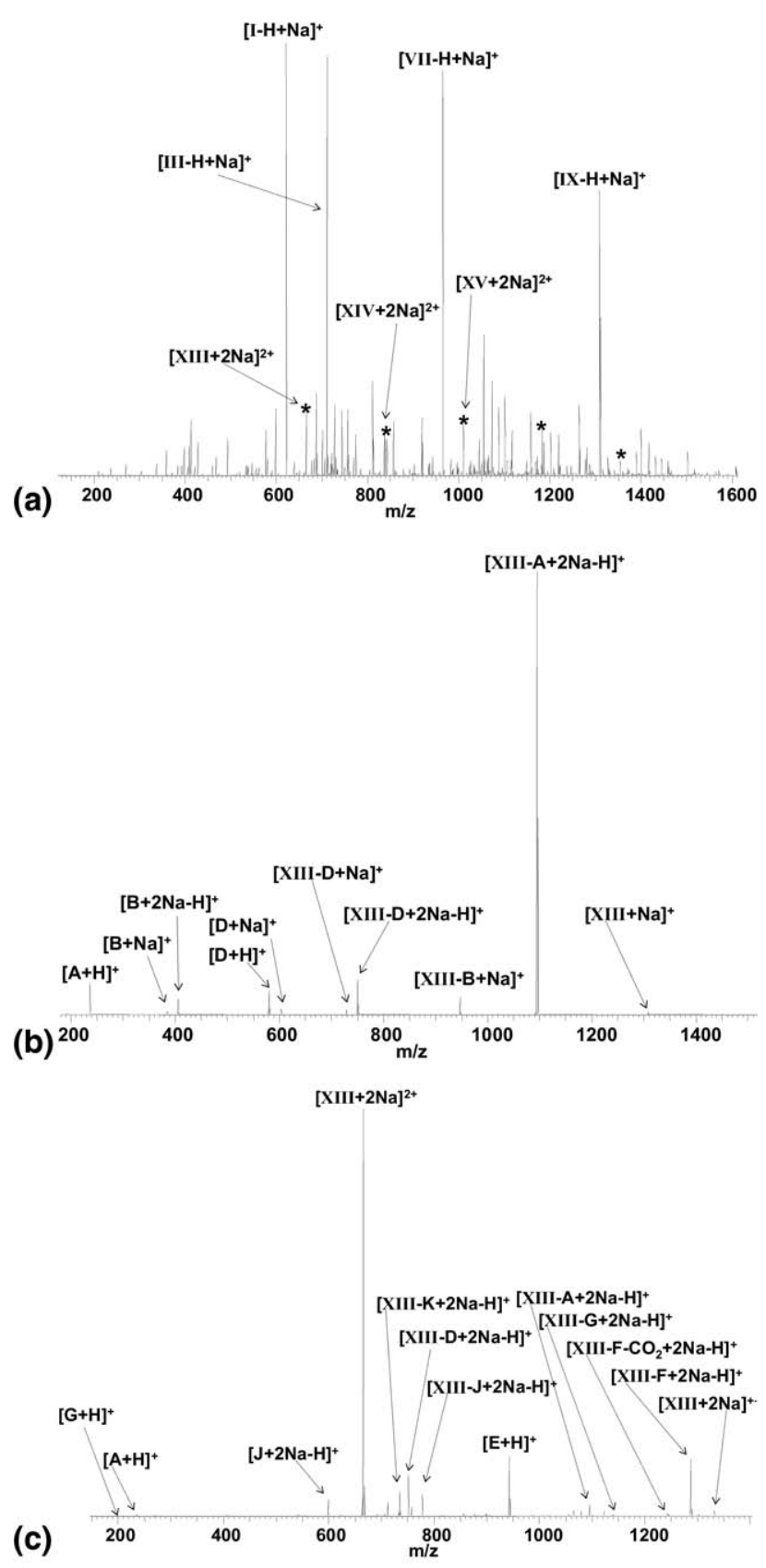

Figure 3. (a) Electrospray FT-ICR mass spectrum of poly[1,4bis(hydroxyethyl)terephthalate-alt-ethyloxyphosphate] in methanol/chloroform/aqueous NaI solution (doubly-sodiated ions are denoted with an asterisk); (b) CID FT-ICR mass spectrum and (c) ECD FT-ICR mass spectrum of doubly-charged [XIII $+2 \mathrm{Na}]^{2+}$ ions. 
observed polymer ions are the result of combinations of those degradation reactions. However, some of the degradation products are solely the result of cleavage at phosphate-[1,4-bis(hydroxyethyl)terephthalate] bonds (route 1, Scheme 3 ). Minor products of degradation processes in which phosphate groups were not involved were also observed.

As described, electrospray ionization of chloroform/methanol solutions of poly[1,4-bis(hydroxyethyl) terephthalate-alt-ethyloxyphosphate] results in the formation of singly-charged ions. To promote cationization of the polyphosphoester, sodium iodide, dissolved in water, was added to the electrospray solution. The mass spectrum, shown in Figure 3a, is dominated by singly-sodiated ions analogous to those seen for protonated [1,4-bis (hydroxyethyl)terephthalate-alt-ethyloxyphosphate] (Figure 1a). Additionally, doubly-charged ions, comprising disodiated polyphosphoester species containing a mixture of phosphate/ethyloxyphosphate groups, were observed. No doubly-charged species containing one sodium cation and one proton were observed. The structure of the simplest doubly-charged ion observed: $[\mathrm{XIII}+2 \mathrm{Na}]^{2+}$, which contains one ethyloxyphosphate and two phosphate groups, is shown in Scheme 4 . The results of the CID and ECD experiments described below suggest that the ethyloxyphosphate group is located between the phosphate groups in the polyphosphoester backbone. Other doubly-charged ions (denoted *, Figure 3a) containing ethyloxyphosphate and phosphate groups, in various stoichiometries, were also observed. For example, species XIV (see Figure 3a, Scheme 4) contains two phosphate groups and two ethyloxyphosphate groups. Species XV contains two ethyloxyphosphate groups and three phosphate groups (Scheme 4). For all the doubly-charged polyphos- phoester ions observed, the number of phosphate groups exceeded that of ethyloxyphosphate groups. That observation can be explained on the basis of the stability of the degradation products; hydrolysis of phosphate-ethoxy bonds leads to formation of phosphate diesters, which are more stable than phosphate triesters [1]. Doubly-charged PPE ions containing up to seven ethyloxyphosphate/phosphate groups were observed.

The CID MS/MS spectrum obtained for [XIII + $2 \mathrm{Na}]^{2+}$ precursor ions is shown in Figure $3 \mathrm{~b}$. The fragments observed are summarized in Table 1 and illustrated in Scheme 5. The most abundant peak at $\mathrm{m} / \mathrm{z}$ 1095.1749 corresponds to [XIII $-\mathrm{A}+2 \mathrm{Na}-\mathrm{H}]^{+}$ions. The complementary ion, $[\mathrm{A}+\mathrm{H}]^{+}$, is present in the MS/MS spectrum at $m / z$ 237.0756. The spectrum also shows peaks corresponding to singly-charged $[\mathrm{B}+$ $\mathrm{Na}^{+}$and $[\mathrm{D}+\mathrm{H}]^{+}$fragments, and their complementary fragments, at $\mathrm{m} / \mathrm{z} 385.0656,581.1412$, 947.1894, 751.1129, respectively. Fragments deriving from loss of neutral A, B, and D from precursor [XIII $+2 \mathrm{Na}]^{2+}$ were not observed. CID cleavage of type $A$ and $B$, i.e., cleavages between carbon atoms, followed by hydrogen transfer (six center pericyclic reactions), was also observed for singly-protonated I and III whereas cleavage of type $\mathrm{D}$, i.e., cleavage of the $\mathrm{CH}_{2}-\mathrm{O}$ bond adjacent to the phosphate group, was not. Unlike CID of the singly-protonated species, CID of the disodiated species provided additional information in the form of complementary fragments.

The ECD MS/MS spectrum of $[\mathrm{XIII}+2 \mathrm{Na}]^{2+}$ is shown in Figure 3c. The fragments observed are summarized in Table 2 and illustrated in Scheme 5. As typically observed in ECD, the MS/MS spectrum is dominated by the peak corresponding to the precursor

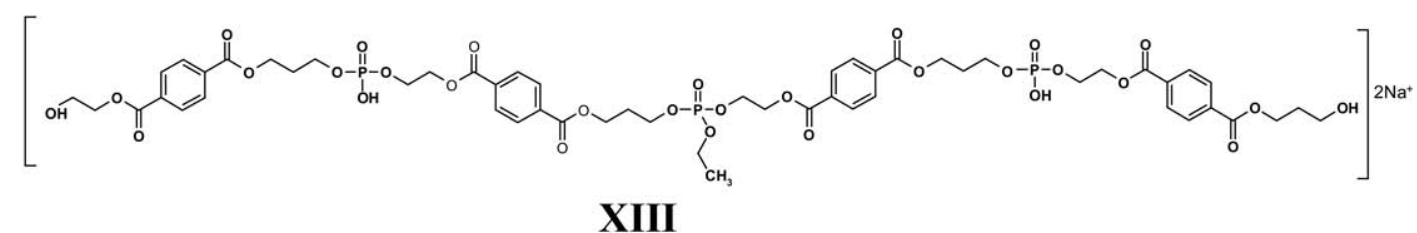

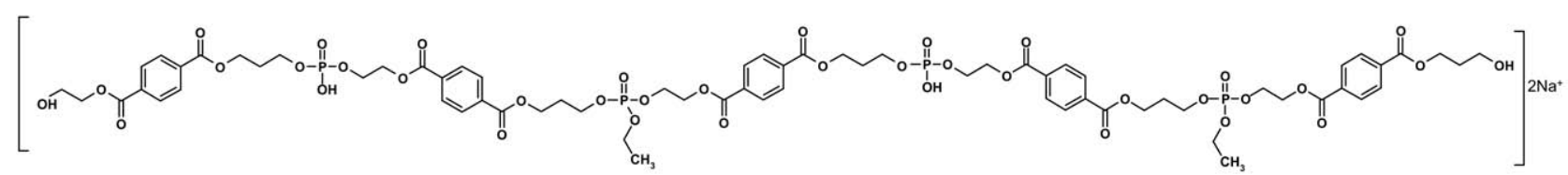

XIV

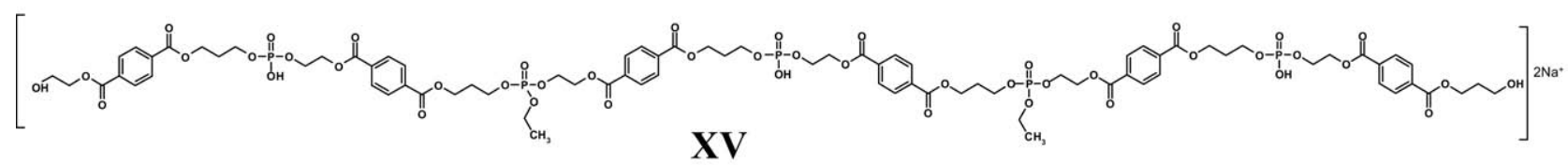

Scheme 4. Structures of disodiated degradation products of poly[1,4 bis(hydroxyethyl)terephthalate-alt-ethyloxyphosphate]. 
Table 1. Masses of fragments observed following collision-induced dissociation of $[\mathrm{XIII}+2 \mathrm{Na}]^{2+}$

\begin{tabular}{ccl}
\hline$m / z$ (measured) & $m / z$ (calculated) & \multicolumn{1}{c}{ Assignment } \\
\hline \hline 237.0756 & 237.0763 & {$[\mathrm{~A}+\mathrm{H}]^{+}$} \\
385.0656 & 385.0665 & {$[\mathrm{~B}+\mathrm{Na}]^{+}$} \\
407.0476 & 407.0485 & {$[\mathrm{~B}+2 \mathrm{Na}-\mathrm{H}]^{+}$} \\
581.1412 & 581.1424 & {$[\mathrm{D}+\mathrm{H}]^{+}$} \\
603.1232 & 603.1244 & {$[\mathrm{D}+\mathrm{Na}]^{+}$} \\
729.1313 & 729.1321 & {$[\mathbf{X I I I}-\mathrm{D}+\mathrm{Na}]^{+}$} \\
751.1129 & 751.1146 & {$[\mathbf{X I I I}-\mathrm{D}+2 \mathrm{Na}-\mathrm{H}]^{+}$} \\
947.1894 & 947.1905 & {$[\mathbf{X I I I}-\mathrm{B}+\mathrm{Na}]^{+}$} \\
1095.1749 & 1095.1807 & {$[\mathbf{X I I I}-\mathrm{A}+2 \mathrm{Na}-\mathrm{H}]^{+}$} \\
1309.2622 & 1309.2672 & {$[\mathbf{X I I I}+\mathrm{Na}]^{+}$} \\
& &
\end{tabular}

Cleavage sites are described in Scheme $\mathbf{5}$.

ion $(m / z 666.1279)$. The peak at $m / z 1332.2581$ corresponds to the charge-reduced precursor [XIII + $2 \mathrm{Na}]^{+}$. Fragments corresponding to loss of neutral A and D (see Scheme 5, Table 2) from the charge-reduced precursor ions are observed; peaks at $m / z 1095.1813$ and 751.1141, respectively. One complementary fragment ion was observed; $[\mathrm{A}+\mathrm{H}]^{+}$at $m / z$ 237.0757. To confirm that fragmentation was not due to coincidental CID, we performed the experiment with zero electron energy. No fragments were observed. The most abundant product of electron capture is observed at $m / z 943.1569$ and corresponds to an internal fragment (labeled $\mathrm{E}$ in Scheme 5) originating from cleavage of two $\mathrm{CH}_{2}-\mathrm{O}$ bonds adjacent to terephthalate groups. The peak observed at $m / z$ 1287.2242 also corresponds to a fragment arising through cleavage of the $\mathrm{CH}_{2}-\mathrm{O}$ bond adjacent to the terminal terephthalate group, labeled $\mathrm{F}$ in Scheme 5. Cleavage of these bonds was not observed following CID, however similar fragmentation behavior has been reported for ECD of cyclodepsipeptides [23]. Peaks observed at $m / z 193.0494$ and 1139.2103 correspond to fragments arising through cleavage of the $\mathrm{C}(\mathrm{O})-\mathrm{O}$ bond in the terminal terephthalate group (labeled $G$ in Scheme 5). Fragments arising following cleavage of $C-C$
Table 2. Masses of fragments observed following electron capture dissociation of [XIII $+2 \mathrm{Na}]^{2+}$

\begin{tabular}{|c|c|c|}
\hline m/z (measured) & $m / z$ (calculated) & Assignment \\
\hline 193.0494 & 193.0501 & {$[\mathrm{G}+\mathrm{H}]^{+}$} \\
\hline 237.0757 & 237.0763 & {$[\mathrm{~A}+\mathrm{H}]^{+}$} \\
\hline 599.0902 & 599.0907 & {$[\mathrm{~J}+2 \mathrm{Na}-\mathrm{H}]^{+}$} \\
\hline 666.1279 & 666.1285 & Parent $[\mathrm{XIII}+2 \mathrm{Na}]^{2+}$ \\
\hline 735.1195 & 735.1197 & {$[\mathrm{XIII}-\mathrm{K}+2 \mathrm{Na}-\mathrm{H}]^{+}$} \\
\hline 751.1141 & 751.1146 & {$[\mathrm{XIII}-\mathrm{D}+2 \mathrm{Na}-\mathrm{H}]^{+}$} \\
\hline 778.1378 & 778.1375 & {$[\mathrm{XIII}-\mathrm{J}+2 \mathrm{Na}-\mathrm{H}]^{+}$} \\
\hline 943.1569 & 943.1592 & {$[\mathrm{E}+\mathrm{H}]^{+}$} \\
\hline 1095.1814 & 1095.1807 & {$[\text { XIII }-\mathrm{A}+2 \mathrm{Na}-\mathrm{H}]^{+}$} \\
\hline 1139.2103 & 1139.2069 & {$[\mathrm{XIII}-\mathrm{G}+2 \mathrm{Na}-\mathrm{H}]^{+}$} \\
\hline 1243.2332 & 1243.2332 & {$\left[\mathrm{XIII}-\mathrm{F}-\mathrm{CO}_{2}+2 \mathrm{Na}-\mathrm{H}\right]^{+}$} \\
\hline 1287.2242 & 1287.2230 & {$[\mathrm{XIII}-\mathrm{F}+2 \mathrm{Na}-\mathrm{H}]^{+}$} \\
\hline 1332.2588 & 1332.2570 & {$[\mathrm{XIII}+2 \mathrm{Na}]^{+}$} \\
\hline
\end{tabular}

Cleavage sites are described in Scheme $\mathbf{5}$.

bonds ( $\mathrm{J}$ on Scheme 5) were observed at $\mathrm{m} / \mathrm{z} 599.0902$ and 778.1378. Finally, the peak at $m / z 735.1195$ corresponds to a fragment arising through cleavage of a $\mathrm{P}-\mathrm{O}$ bond in the phosphate group (labeled $\mathrm{K}$ in Scheme 5). Such fragmentation behavior is in stark contrast to that observed in the ECD of phosphopeptides. ECD of phosphopeptides does not result in cleavage within the phosphate [24, 25].

\section{Conclusions}

The results show that FT-ICR mass spectrometry may be successfully applied to the characterization of polyphosphoesters and their degradation products. The findings suggest that degradation of the polyphosphoester poly[1,4bis(hydroxyethyl)terephthalate-alt-ethyloxyphosphate] occurs mainly via hydrolysis of the phosphate-[1,4bis(hydroxyethyl)terephthalate] and phosphate-ethoxy bonds. Minor degradation processes in which ethyloxyphosphate groups were not involved was also observed. CID of both singly-protonated and disodiated PPE ions

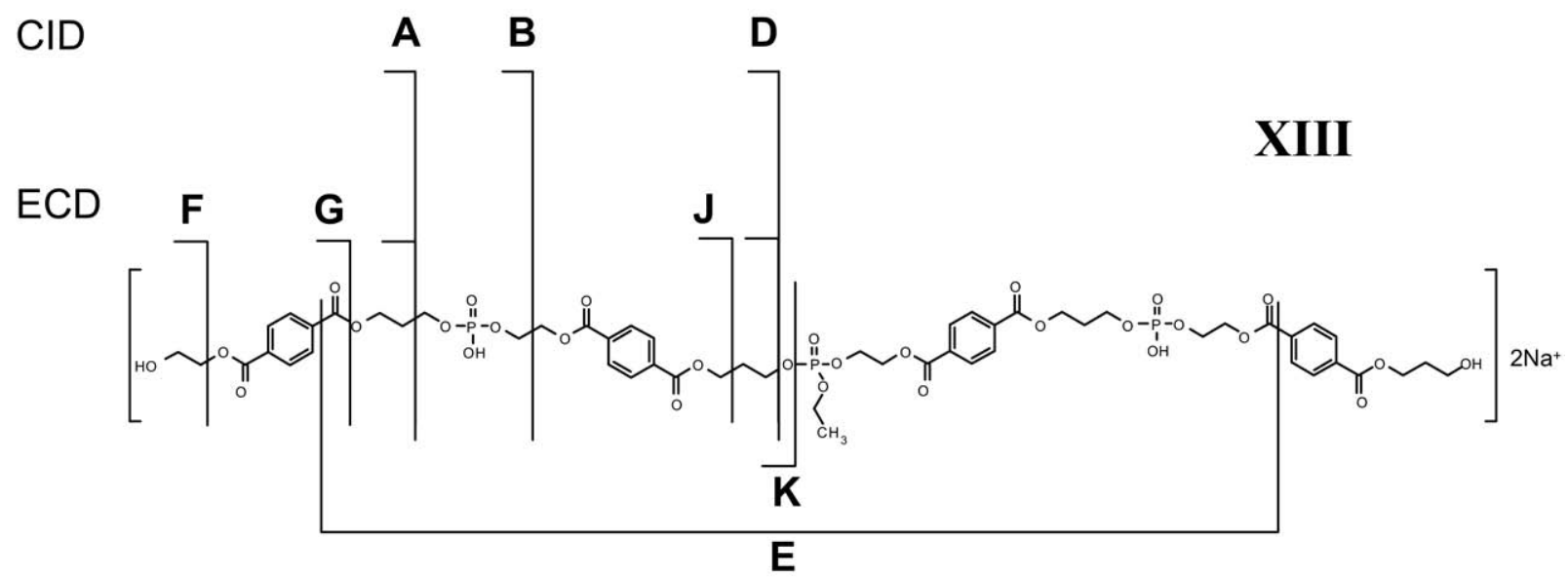

Scheme 5. Cleavage sites observed following CID and ECD of disodiated degradation product XIII. 
was characterized by cleavage of polymer backbone $\mathrm{C}-\mathrm{C}$ bonds. ECD of the $[\mathrm{XIII}+2 \mathrm{Na}]^{2+}$ ions resulted in a larger number of fragments than did CID. Although C-C cleavage is observed on ECD, the predominant fragmentation pathway involves cleavage of one or more $\mathrm{CH}_{2}-\mathrm{O}$ bonds adjacent to the terephthalate. Both fragmentation methods provide detailed and complementary information about the structure of the PPE degradation products.

\section{Acknowledgments}

The authors gratefully acknowledge EPSRC and the Wellcome Trust (074131) for funding.

\section{References}

1. Zhao, Z.; Wang, J.; Mao, H. Q.; Leong, K. W. Polyphosphoesters in Drug and Gene Delivery. Adv. Drug. Del. Rev. 2003, 55(4), 483-499.

2. Chaubal, M. V.; Sen Gupta, A.; Lopina, S. T.; Bruley, D. F. Polyphosphates and Other Phosphorus-Containing Polymers for Drug Delivery Applications. Crit. Rev. Ther. Drug Carrier Sys. 2003, 20(4), 295-315.

3. Wang, S.; Wan, A. C. A.; Xu, X. Y.; Gao, S. J.; Mao, H. Q.; Leong, K. W.; Yu, H. A New Nerve Guide Conduit Material Composed of a Biodegradable Poly(Phosphoester). Biomaterials 2001, 22(10), 1157-1169.

4. Lu, Z. Z.; Wu, J.; Sun, T. M.; Ji, J.; Yan, L. F.; Wang, J. Biodegradable Polycation and Plasmid DNA Multilayer Film for Prolonged Gene Delivery to Mouse Osteoblasts. Biomaterials 2008, 29(6), 733-741.

5. Wang, J.; Huang, S. W.; Zhang, P. C.; Mao, H. Q.; Leong, K. W. Effect of Side-Chain Structures on Gene Transfer Efficiency of Biodegradable Cationic Polyphosphoesters. Int. J. Pharm. 2003, 265, 75-84.

6. Wang, J.; Mao, H. Q.; Leong, K. W. A Novel Biodegradable Gene Carrier Based on Polyphosphoester. J. Am. Chem. Soc. 2001, 123(38), 9480-9481.

7. Reddi, A. H. Symbiosis of Biotechnology and Biomaterials-Applications in Tissue Engineering of Bone and Cartilage. J. Cell. Biochem. 1994, 56(2), 192-195.

8. Wang, D. A.; Williams, C. G.; Yang, F.; Cher, N.; Lee, H.; Elisseeff, J. H. Bioresponsive Phosphoester Hydrogels for Bone Tissue Engineering. Tissue Eng. 2005, 11(1/2), 201-213.

9. Wang, Y. C.; Tang, L. Y.; Sun, T. M.; Li, C. H.; Xiong, M. H.; Wang, J. Self-Assembled Micelles of Biodegradable Triblock Copolymers Based on Poly(Ethyl Ethylene Phosphate) and Poly(Epsilon-Caprolactone) as Drug Carriers. Biomacromolecules 2008, 9(1), 388-395.
10. Li, Q.; Wang, J.; Shahani, S.; Sun, D. D. N.; Sharma, B.; Elisseeff, J. H.; Leong, K. W. Biodegradable and Photocrosslinkable Polyphosphoester Hydrogel. Biomaterials 2006, 27(7), 1027-1034.

11. Iwasaki, Y.; Wachiralarpphaithoon, C.; Akiyoshi, K. Novel Thermoresponsive Polymers Having Biodegradable Phosphoester Backbones. Macromolecules 2007, 40(23), 8136-8138.

12. Renier, L. M.; Kohn, D. H. Development and Characterization of a Biodegradable Polyphosphate. J. Biomed. Mater. Res. 1997, 34(1), 95-104.

13. Ignatius, A. A.; Claes, L. E. In Vitro Biocompatibility of Bioresorbable Polymers: Poly(L,DL-Lactide) and Poly(L-Lactide-Co-Glycolide). Biomaterials 1996, 17(8), 831-839.

14. McEwen, C. N.; Peacock, P. M. Mass Spectrometry of Chemical Polymers. Anal. Chem. 2002, 74, 2743-2748.

15. Hanton, S. D. Mass Spectrometry of Polymers and Polymer Surfaces. Chem. Rev. 2001, 101(2), 527-569.

16. Simonsick, W. J. J.; Petkovska, V. I. Detailed Structural Elucidation of Polyesters and Acrylates Using Fourier Transform Mass Spectrometry. Anal. Bioanal. Chem. 2008, 392(4), 575-583.

17. Cerda, B. A.; Horn, D. M.; Breuker, K.; McLafferty, F. W. Sequencing of Specific Copolymer Oligomers by Electron Capture Dissociation Mass Spectrometry. J. Am. Chem. Soc. 2002, 124, 9287-9291.

18. Cerda, B. A.; Breuker, K. Horn, D. M.; McLafferty, F. W. Charge/ Radical Site Initiation Versus Coulombic Repulsion for Cleavage of Multiply Charged Ions. Charge Solvation in Poly(Alkene Glycol) Ions. J. Am. Soc. Mass Spectrom. 2000, 12(5), 565-570.

19. Kaczorowska, M. A.; Cooper, H. J. ECD, EDD, and CID of PAMAM Dendrimer Ions with Amino, Amidoethanol, and Sodium Carboxylate Surface Groups. J. Am. Soc. Mass Spectrom. 2008, 19, 1312-1319.

20. Kaczorowska, M. A.; Cooper, H. J. Electron Capture Dissociation and Collision-Induced Dissociation of Metal Ion $[\mathrm{Ag}(+), \mathrm{Cu}(2+), \mathrm{Zn}(2+)$ $\mathrm{Fe}(2+)$, and $\mathrm{Fe}(3+)]$ Complexes of Polyamidoamine (PAMAM) Dendrimers. J. Am. Soc. Mass Spectrom. 2009, 20(4), 674-681.

21. Lee, S.; Han, S. Y.; Lee, T. G.; Chung, G.; Lee, D.; Oh, H. B. Observation of Pronounced B-Dot, y Cleavages in the ECD Mass Spectrometry of PAMAM Dendrimer Ions with Amide Functionalities. J. Am. Soc. Mass Spectrom. 2006, 17, 536-543.

22. Chaubal, M. V.: Su, G.; Spicer, E.; Dang, W. B.; Branham, K. E.; English J. P.; Zhao, Z. In Vitro and In Vivo Degradation Studies of a Novel Linear Copolymer of Lactide and Ethylphosphate. J. Biomat. Sci. Polym. 2003, 14(1), 45-61.

23. Cooper, H. J.; Hudgins, R. R.; Marshall, A. G. Electron Capture Dissociation of Cyclodepsipeptides, Branched Peptides and $\varepsilon$-Peptides. Int. J. Mass Spectrom. 2004, 234, 24-35.

24. Stensballe, A.; Jensen, O. N.; Olsen, J. V.; Haselmann, K. F.; Zubarev, R. A. Electron Capture Dissociation of Singly and Multiply Phosphorylated Peptides. Rapid Commun. Mass Spectrom. 2000, 14(19), 1793-1800.

25. Shi, S. D. H.; Hemling, M. E.; Carr, S. A.; Horn, D. M.; Lindh, I. McLafferty, F. W. Phosphopeptide/Phosphoprotein Mapping by Electron Capture Dissociation Mass Spectrometry. Anal. Chem. 2001, 73(1), $19-22$. 